\title{
Recent advances in understanding plant response to sulfur-deficiency stress
}

\author{
Małgorzata Lewandowska and Agnieszka Sirko ${ }^{\bowtie}$ \\ Institute of Biochemistry and Biophysics, Polish Academy of Sciences, Warszawa, Poland
}

Received: 08 July, 2008; revised: 11 August, 2008; accepted: 11 September, 2008 available on-line: 12 September, 2008

\begin{abstract}
Sulfur is an essential macronutrient for all living organisms. Plants are able to assimilate inorganic sulfur and incorporate it into organic compounds, while animals rely entirely on organic sources of sulfur. In the last decades sulfate availability in soils has become the major limiting factor for plant production in many countries due to significant reduction of anthropogenic sulfur emission forced by introducing stringent environmental legislation. The sulfur flux after transferring plants from optimal conditions to sulfur deficiency is regulated on multiple levels including transcription, translation and activity of enzymes needed for sulfate assimilation and synthesis of sulfur-containing metabolites. Most of these regulatory steps are not yet fully characterized. Plant responses to sulfur limitation are complex and can be divided into phases depending on the degree of sulfur shortage. The initial responses are limited to adaptations within sulfur metabolic pathway, while multiple metabolic pathways and developmental process are affected when sulfur shortage becomes more severe. The major aim of this work is a comprehensive review of recent progress in understanding the regulation of plant adaptations to sulfur deficit.
\end{abstract}

Keywords: cysteine, glutathione, nutrient availability, stress response, sulfate assimilation, sulfur metabolism

\section{GLOBAL SULFUR CYCLE, VARIETY OF SULFUR COMPOUNDS AND IMPORTANCE OF SUFFICIENT SULFUR NUTRITION}

Sulfur occurs in the environment in a variety of oxidative states that range from -2 in its most reduced form (sulfide $-\mathrm{S}^{-2}$ ) to +6 in its most oxidized form (sulfate $-\mathrm{SO}_{4}{ }^{2+}$ ). In the aerobic atmosphere of the Earth inorganic sulfur occurs predominantly in the form of sulfate. The main reserve of sulfur are oceans (Giordano et al., 2005; Norici et al., 2005), where sulfur exists primarily in the form of inorganic sulfate, while in the earth sulfur can be found mostly as sulfate minerals, such as gypsum, or sulfide minerals, such as pyrite (Scherer, 2001). Sulfur dioxide $\left(\mathrm{SO}_{2}\right)$, mainly, and hydrogen sulfide $\left(\mathrm{H}_{2} \mathrm{~S}\right)$ are emitted to the atmosphere as a result of volcanic activity, decomposition of biological tissues and anthropogenic activities. All sulfur compounds are in constant flux (termed global sulfur cycle) between oxidized and reduced states through the action of living organisms and chemical processes.

Sulfur is necessary for proper growth and development of living organisms, however, it is attributed rather catalytic and regulatory than structural functions because it is much less abundant than other macroelements. For example, there is on average about 30 -fold more nitrogen, 8-fold more potassium and 2-fold more phosphorus than sulfur in plant shoot dry matter (Marshner, 2005). The plant biomass consumed as food and feed serves as the main source of organic sulfur for animals and humans (Komarnisky et al., 2003). Plants, bacteria and fungi, contrary to animals, are able to assimilate inorganic sulfur and incorporate it into organic compounds. Inorganic sulfur must follow a cascade of reactions

${ }^{\square}$ Corresponding author: A. Sirko, Institute of Biochemistry and Biophysics, Polish Academy of Sciences, ul. Adolfa Pawinskiego 5A, 02-106 Warszawa, Poland; tel.: (48 22) 658 4801; fax: (48 22) 658 4804; e-mail: asirko@ibb.waw.pl

Abbreviations: ATPS, ATP sulfurylase; APR, ATS reductase; APS, adenosine 5'-phosphosulfate; CS, cysteine synthase; GSH, glutathione; OAS, O-acetyl-L-serine; OAS-TL, O-acetylserine (thiol)lyase; SAM, S-adenosylmethionine; SAT, serine acetyltransferase 
to be changed into organic sulfur compounds. It can be either directly incorporated in a reaction termed sulfation or used as a substrate for the synthesis of cysteine after a multistep reduction to sulfide. The sulfate assimilation pathway was first resolved in enteric bacteria, Escherichia coli and Salmonella typhimurium (for review see Kredich, 1996) and it was subsequently characterized in plants.

Plants utilize sulfate for the synthesis of diverse primary and secondary metabolites (Fig. 1). The first organic compound synthesized in the sulfate assimilatory pathway is cysteine (Cys). It is an important amino acid incorporated into various proteins, and a precursor of numerous essential compounds such as methionine, S-adenosylmethionine (SAM), S-methylmethionine, [Fe/S] clusters, hormones, vitamins and enzyme cofactors. Disulfide bonds formed in proteins between the thiol groups of Cys residues play crucial roles in forming and maintaining the tertiary structures of proteins. Some Cys-containing metabolites, including glutathione (GSH), phytochelatins and thionins function in response against environmental stresses. Organic compounds containing sulfur are also responsible for the specific taste and smell of onion, garlic and other valuable vegetables and herbs used in the kitchen or in traditional medicine.

Over the last decades it has become obvious that sulfur availability is limiting for farming in some parts of the world. Paradoxically, it is a result of a positive phenomenon, namely, a strong reduction of atmospheric pollution in industrialized areas of developed countries. The local trends to reduce sulfur dioxide $\left(\mathrm{SO}_{2}\right)$ emission all over the world vary from one region to another and are the results of environmental legislations imposed by local governments. In the majority of European countries, including Poland, emission has decreased by more than $60 \%$ in the years 1990-2004 (Vestreng et al., 2007), while in Asia these trends are still reversed comparing to Europe and USA. Both the reduction of sulfur emission to the atmosphere resulting in a decrease of atmospheric sulfur deposition onto agricultural land and the use of sulfur-free (but rich in nitrogen and phosphorus) fertilizers have led to insufficient sulfur supply to a variety of crops, especially those with high sulfur requirements (e.g., oilseed rape). Insufficient sulfate nutrition reduces plant growth, vigor and resistance to abiotic and biotic stresses (Scherer, 2001; Knop et al., 2007; Kruse et al., 2007). Sulfur deficit influences not only the crop yield but also food quality. For example, certain sulfur-rich proteins in wheat determine the backing quality of flour (Zhao et al., 1999; Granvogl et al., 2007) and malting quality of barley (Zhao et al., 2006). A decreased sulfur content in wheat may increase the level of cancerogenic acrylamide in processed food (Muttucumaru et al., 2006). Additionally, a sufficient metabolic supply of sulfur amino acids from diet and tissue protein breakdown is necessary for the normal functioning of animals, including the mammalian immune system (Grimble, 1994; Hunter \& Grimble, 1997).

Sulfur starvation which decreases the level of sulfur-containing defense compounds, such as elemental sulfur, $\mathrm{H}_{2} \mathrm{~S}$, glutathione, phytochelatins, various secondary metabolites and sulfur-rich proteins, is apparently associated with a decreased resistance of plants, while sulfur fertilization of plants increases their resistance to pathogens and stresses. This process was termed sulfur-induced resistance - SIR (Rausch \& Wachter, 2005; Kruse et al., 2007). Conversely, environmental stresses resulting in increased formation of reactive oxygen species and oxidative stress have an influence on sulfur metabolism.

The biochemistry of sulfur assimilation is well characterized, however, many questions remain unsolved concerning regulation of sulfur metabolism in response to both the availability of sulfur in the environment and the increased demand of plants for sulfur metabolites in certain environmental conditions. Keeping in mind the common occurrence of sulfur deficiency in soils it is extremely important to understand the molecular mechanisms of plant response to the changing conditions of sulfur nutrition. The recent progress in the understanding of the complexity of plant adaptation to sulfur deficit was possible due to application of a variety of approaches, including systems biology methods, by multiple research groups interested in the field.

\section{SULFATE UPTAKE AND SULFUR METABOLIC PATHWAY}

The Arabidopsis thaliana genes encoding proteins involved in sulfate uptake, its translocation within plants and selected steps of sulfur metabolism are listed in Table 1. Most of the enzymes of the pathway are encoded by multigene families. The redundancy and multi-compartment location of the enzymes responsible for most of the steps are, on one hand, an indication of the importance of adequate control of sulfur flux and, on the other hand, illustrate the complexity of the system. A general scheme of sulfate assimilation and sulfur metabolism in plants is shown in Fig. 1. Provided below is a short outline of the pathway, which is necessary for understanding the regulatory aspects discussed in the next chapters, and brief descriptions of the problems not covered in earlier reviews. The readers interested in details of the pathway biochemistry are referred to the numer- 
Table 1. Proteins from Arabidopsis thaliana involved in the major steps of sulfur metabolism compiled according to TAIR database (http://www.arabidopsis.org/index.jsp)

\begin{tabular}{|c|c|c|}
\hline Protein function & Genome locus & Protein name; alternative names \\
\hline \multirow[t]{14}{*}{ Sulfate transporter (ST) } & At4g08620 & SULTR1;1 \\
\hline & At1g78000 & SULTR1;2 \\
\hline & At1g22150 & SULTR1;3 \\
\hline & At5g10180 & SULTR2;1 \\
\hline & At1g77990 & SULTR2;2 \\
\hline & At3g51895 & SULTR3;1 \\
\hline & At4g02700 & SULTR3;2 \\
\hline & At1g23090 & SULTR3;3 \\
\hline & At3g15990 & SULTR3;4 \\
\hline & At5g19600 & SULTR3;5 \\
\hline & At5g13550 & SULTR $4 ; 1$ \\
\hline & At3g12520 & SULTR4;2 \\
\hline & At1g80310 & SULTR5;1 \\
\hline & At2g25680 & SULTR5;2 \\
\hline \multirow[t]{4}{*}{ ATP sulfurylase (ATPS); EC 2.7.7.4 } & At3g22890 & APS1; ATP sulfurylase 3 \\
\hline & At1g19920 & APS2; ATP sulfurylase 1 \\
\hline & At4g14680 & APS3; ATP sulfurylase 2 \\
\hline & At5g 43780 & APS4 \\
\hline \multirow[t]{4}{*}{ Adenylsulfate kinase (APSK); EC 2.7.1.25 } & At2g14750 & AKN1 \\
\hline & At4g39940 & AKN2 \\
\hline & At3g03900 & APS kinase, putative \\
\hline & At5g67520 & APS kinase, putative \\
\hline \multirow[t]{3}{*}{ APS reductase (APR); EC 1.8.99.2 } & At4g04610 & APR1 \\
\hline & At1g62180 & APR2 \\
\hline & At4g21990 & APR3 \\
\hline Sulfite reductase (SiR); EC 1.8.99.1 & At5g04590 & SIR \\
\hline \multirow{9}{*}{$\begin{array}{l}\text { O-Acetylserine (thiol)-lyase (OAS-TL); } \\
\text { EC 2.5.1.47 }\end{array}$} & At4g14880 & OASA1; ATCYS-3A \\
\hline & At2g43750 & OASB; ACS1; ATCS-B \\
\hline & At3g59760 & OASC; ATCS-C \\
\hline & At3g61440 & ATCYSC1; BSAS3;1 \\
\hline & At3g04940 & ATCYSD1 \\
\hline & At5g28020 & ATCYSD2 \\
\hline & At3g03630 & CS26 \\
\hline & At3g22460 & OAS-TL, putative \\
\hline & At5g28030 & OAS-TL, putative \\
\hline \multirow[t]{5}{*}{ Serine acetyltransferase (SAT); EC 2.3.1.30 } & At1g55920 & SAT1; SAT B; SAT5 AtSerat2;1 \\
\hline & At2g17640 & SAT2; SAT-106; AtSerat3;1 \\
\hline & At3g13110 & SAT3; SAT A; SAT-1; AtSerat2;2 \\
\hline & At4g35640 & SAT4; AtSerat3;2 \\
\hline & At5g56760 & SAT5; SAT C;SAT-52; AtSerat1;1 \\
\hline $\begin{array}{l}\text { Glutamino-cysteine lyase (GCL); EC 6.3.2.2 } \\
/ \gamma \text {-glutamylcysteine synthetase ( } \gamma \text {-ECS) }\end{array}$ & At4g23100 & GSH1; RML1; CAD2; PAD2 \\
\hline Glutatione synthetase (GSHS); EC 6.3.2.3 & At5g27380 & GSH2; GSHB \\
\hline Sulfite oxidase (SOX); EC 1.8.3.1 & At3g01910 & SOX \\
\hline \multirow{2}{*}{$\begin{array}{l}\text { Cystathionine } \gamma \text {-synthase (CGS); } \\
\text { EC 2.5.1.48 }\end{array}$} & At3g01120 & CGS; CGS1; MTO1 \\
\hline & At1g33320 & Similar to MTO1 \\
\hline Cystathionine $\beta$-lyase (CBL); EC 4.4.1.8 & At3g57050 & CBL \\
\hline \multirow[t]{3}{*}{ Methionine synthase (MS); EC 2.1.1.14 } & At5g17920 & ATMS1 \\
\hline & At3g03780 & ATMS2 \\
\hline & At5g20980 & ATMS3 \\
\hline
\end{tabular}

ous excellent reviews on the subject (Hell \& Hillebrand, 2001; Leustek, 2002; Kopriva \& Koprivova, 2003; Saito, 2004; Hawkesford \& De Kok, 2006; Kopriva, 2006; Kopriva et al., 2007).

\section{Uptake and redistribution of sulfate}

Inorganic sulfate is the primary source of sulfur used by plants. Plants have evolved a network 


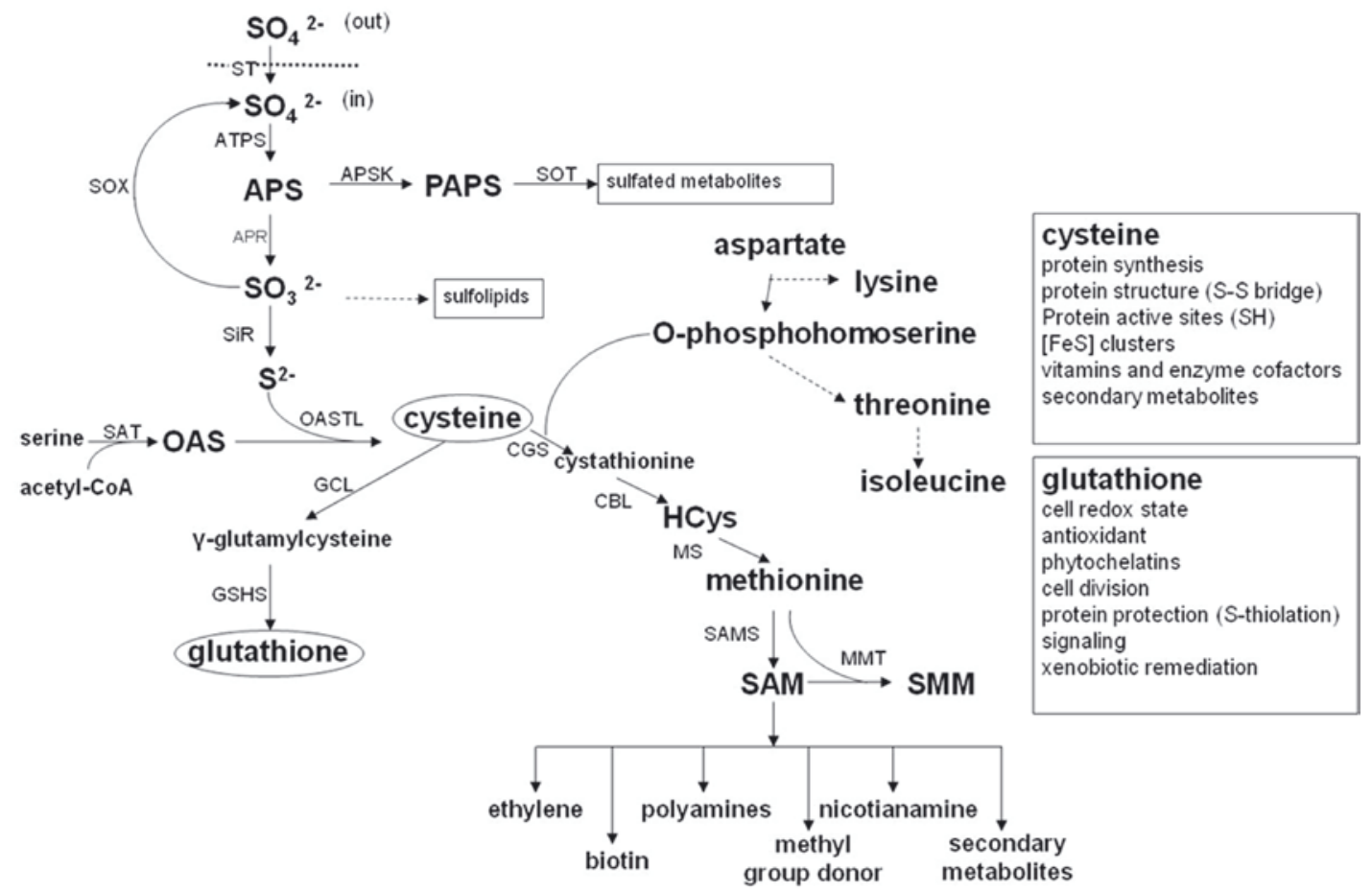

Figure 1. Outline of sulfate assimilation and cysteine metabolism in plants.

Enzymes involved in sulfate and sulfite reduction are present only in plastids, while SAT and OAS-TL are present in plastids, mitochondria and cytosol. Enzymes involved in GSH synthesis are present in chloroplasts and in extrachloroplast fractions. The first two steps of methionine synthesis proceed only in plastids, while the third step only in cytosol because of strictly cytosolic location of MS. APSK, APS kinase; APR, APS reductase; APS, adenosine 5'-phosphosulfate; ATPS, ATP sulfurylase; CBL, cystathionine $\beta$-lyase; CGS, cystathionine $\gamma$-synthase; GCL, glutamino-cysteine lyase; GSHS, glutathione synthetase; HCys, homocysteine; MMT, S-adenosylmethionine:L-methionine S-methyltransferase; MS, methionine synthase; OAS, O-acetylserine; OAS-TL, O-acetylserine (thiol)-lyase; PAPS, adenosine 3'-phosohate 5'-phosphosulfate; SAM, S-adenosylmethionine; SAMS, SAM synthetase; SAT, serine acetyltransferase; SMM, S-methylmethionine; SiR, sulfite reductase; SOX, sulfite oxidase; SOT, sulfotransferase; ST, sulfate transporter.

of sulfate transporters with different affinity, localization and regulation enabling efficient uptake and distribution of sulfur from root cells into sink organs according to the availability of sulfur and the plant's requirements. Plant sulfate transporters are classified into five groups depending on their protein sequences and characteristics (for review and references see: Hawkesford, 2003). In A. thaliana, the family of sulfate transporters (encoded by 14 genes) is larger than that of transporters for nitrate (7 genes), inorganic phosphate (9 genes) or ammonium (6 genes). The best characterized are sulfate transporters from the first group, AtSULTR1;1 and AtSULTR1;2, which are expressed in root hairs and root epidermal and cortical cells (Takahashi et al., 2000; Vidmar et al., 2000; Yoshimoto et al., 2002; 2007; El Kassis et al., 2007). These high-affinity transporters function in the uptake of sulfate from soil. AtSULTR2;1, AtSULTR2;2 (both from group 2) and AtSULTR1;3 (from group 1) are lower-affinity transporters localized in xylem parenchyma and phloem cells of roots and take part in long-distance transport during the source-to-sink translocation. AtSULTR4;1 and AtSULTR4;2, belonging to group
4, are localized in tonoplasts of pericycle and $x y-$ lem parenchyma cells of roots and hypocotyls and are responsible for sulfate efflux from the vacuole. The role of transporters from group 3 (AtSULTR3;1-AtSULTR3;5) and group 5 (AtSULTR5;1 and AtSULTR5;2) is still not fully clarified.

\section{Sulfate assimilation and cysteine formation}

After uptake, sulfate can be either stored in the vacuole within the cell or further metabolized in a series of steps which occur in plastids and comprise (i) activation by adenylation to adenosine $5^{\prime}$ phosphosulfate (APS) in the reaction catalyzed by ATP sulfurylase (ATPS), (ii) reduction of APS to sulfite in the reaction catalyzed by APS reductase (APR) and (iii) sulfite reduction to sulfide in the reaction catalyzed by sulfite reductase (SiR).

Alternatively, APS can be phosphorylated by APS kinase to adenosine 3'-phosphate 5'-phosphosulfate (PAPS), which in turn can be used for the synthesis of sulfated compounds, such as coumarins, glucosinolates, flavonoids, gibberellic acids, hydroxyjasmonates, phenolic acids, steroids or sulfate esters 
by the multiprotein family of sulfotransferases (Klein \& Papenbrock, 2004). PAPS was also proposed to be used as a reservoir for APS, although a convincing proof for the existence of the enzyme capable of converting PAPS into APS in plants is missing (Droux, 2004). In lower plants, like in bacteria, PAPS can be reduced to sulfite by PAPS reductase (Koprivova et al., 2002).

Sulfite reductase (SiR) contains siroheme and iron-sulfur cluster that are necessary for its activity and catalyzes the reduction of sulfite using electrons donated from ferredoxin. In addition to its catalytic function, SiR plays probably another role in plant chloroplasts. It has been reported that $\mathrm{SiR}$ from pea and maize have DNA-binding properties and some results suggest that $\mathrm{SiR}$ is essential for proper compacting of nucleoids in plastids, which influences the transcriptional activity of chloroplast DNA (Sekine et al., 2007). The enzymatic activity of SiR from pea was not affected by binding to DNA, indicating that ferredoxin and sulfite are accessible to $\mathrm{SiR}$ molecules within the nucleoids. It is possible that SiR could act as a sensor of the redox state of the chloroplast, which is connected with regulation of some chloroplast genes by the redox state. Besides, the extent of $\mathrm{SiR}$ association with chloroplast nucleoids varies among plant species.

Interestingly, a molybdoenzyme sulfite oxidase able to produce sulfate from sulfite has been identified recently in plant peroxisomes. This enzyme probably functions as a "safety valve" for detoxifying excess of harmful sulfite and protecting the cells from sulfitolysis (Hansch et al., 2007; Lang et al., 2007).

Two enzymes able to form a complex of cysteine synthase (CS), namely serine acetyltransferase (SAT) and OAS (thiol)-lyase (OAS-TL) are responsible for the next two steps of the pathway. SAT catalyzes synthesis of $O$-acetylserine (OAS) from L-serine and acetyl-CoA, while OAS-TL is responsible for incorporation of sulfur into OAS to synthesize Cys. SAT is a rate-limiting enzyme for biosynthesis of cysteine. Overexpression of SAT in tobacco and potato resulted in increased contents of cysteine and GSH (Blaszczyk et al., 1999; Harms et al., 2000), while overexpression of OAS-TL in Arabidopsis and tobacco caused only moderate increases of Cys and GSH levels (for review see Sirko et al., 2004). In fact, the low ratio of SAT to OAS-TL might be critical for maintaining the strict control of Cys synthesis because also a reduction of OASTL activity in transgenic potato resulted in significant elevation of Cys level (Riemenschneider et al., 2005a). On the other hand, these results suggest that OAS-TL could be responsible for both synthesis and breakdown of Cys. The regulatory functions of the CS complex in controlling the sulfur flux are discussed below.

Degradation of Cys is catalysed by cysteine desulfhydrase and results in pyruvate, ammonia, and $\mathrm{H}_{2} \mathrm{~S}$ production (Papenbrock et al., 2007). The released $\mathrm{H}_{2} \mathrm{~S}$ might play a role in plant defense upon pathogen attack (Rausch \& Wachter, 2005). Several candidates for Cys desulfhydrase, such as NifS-like proteins can be found in A. thaliana (Riemenschneider et al., 2005a; 2005b).

\section{Further metabolism of cysteine}

Cysteine serves not only for protein production, synthesis of methionine (Met) and Met derivatives such as $S$-adenosylmethionine (SAM) and $S$-methylmethionine (SMM), but it is also a branching point for the synthesis of many other sulfur-containing compounds such as glutathione (GSH) or $S$ methylcysteine, S-alkylcysteine, glucosinolates, and phytoalexins (Leustek, 2002).

SAM is a key substrate for numerous enzymes (Fontecave et al., 2004; Roje, 2006). It serves as a donor of methyl group and a source of methylene groups for the synthesis of lipids, pectins, alkaloids, phytosterols, osmoprotectants, precursors of lignins, lignans, suberins, hydroxycinnamic acids, flavonoids, stilbens, various aromatic and volatile fragrance and aroma compounds. The methyl group can be transferred from SAM to a variety of acceptors, including amino-acid residues in proteins, nucleic acids and other molecules. SAM is also a source of reactive $5^{\prime}$ deoxyadenosyl radicals used by numerous enzymes. The amino group of SAM is used in the synthesis of biotin. SAM is also a donor of the aminoisopropyl group in the synthesis of polyamines and a precursor of ethylene, nicotianamine and phytosiderophores.

Glutathione $(\mathrm{GSH})$ is the main form of reduced sulfur transported (through phloem) and stored in plants (Rennenberg et al., 1979). For a long time it has been postulated that GSH acts as an interorgan signal for the sulfur status from shoots to roots (Lappartient et al., 1999; Herschbach et al., 2000). The concentration of GSH is much higher than of free Cys in the cell, what indicates that, being less-reactive than Cys, it is used for storage of reduced sulfur. GSH plays not only an important role in sulfur metabolism, but is also involved in regulation of growth and development of the plant by modulation of such processes as mitosis, cell elongation, senescence, cell death, resistance to environmental stresses, detoxification and maintaining the redox homeostasis. Fundamental to the GSH role is not only its concentration, but also the ratio of its reduced form to the oxidized one. Changes in the GSH pool provide information on the redox state of the cell, which 
might influence expression of genes important in defense against environmental stresses. Increases of the GSH pool have been observed in response to many environmental stresses including pathogen attack or treatment with heavy metals (Foyer \& Noctor, 2005; Noctor, 2006; Wawrzynski et al., 2006), whereas plants with decreased amounts of GSH were more sensitive to a range of environmental stresses, such as heavy metal treatment or oxidative stresses (Xiang \& Oliver, 1998). The regulatory role of GSH in the metabolic control of the sulfur pathway will be discussed below.

$S$-Methylmethionine (SMM) may be used in cereals for long distance transport of reduced sulfur since it was found to be about 1.5-fold more abundant than GSH in phloem sap of wheat (Bourgis et al., 1999).

\section{MULTIPLE LEVELS OF REGULATION OF SULFATE ASSIMILATION PATHWAY}

\section{Current understanding of metabolic control by thi- ols and OAS}

During sulfur limitation the activities of sulfate transporters, ATP sulfurylase (ATPS) and APS reductase (APR) are higher than those observed under optimal sulfur supply. This process is regulated mainly, but not exclusively, at the level of transcription of respective genes (Takahashi et al., 1997; Yamahuchi et al., 1997). It has been known for several decades that GSH, the major organic thiol-containing metabolite, has an important role in regulating sulfur homeostasis. Feeding of plants with thiols, such as Cys and GSH, results in decreased sulfate uptake and reduction as well as reduced expression of genes encoding proteins of the pathway (Smith et al., 1997; Vidmar et al., 1999; Vauclare et al., 2002). Since Cys can be promptly converted in plants into GSH, it is unclear which of these two metabolites takes part in the control of sulfate uptake and assimilation. Experiments conducted in Brassica napus prove that GSH rather than Cys is responsible for such control (Lappartient \& Touraine, 1996; Lappartient et al., 1999), while in maize Cys influences expression of ATPS without the need for conversion to GSH (Bolchi et al., 1999). These contradicting results emphasize that not all models of regulation are common among plant species and they pinpoint the need for investigation of sulfur metabolism in various plants. So far, there is no evidence for a direct negative role of thiols in regulation of expression of the genes involved in sulfate transport and assimilation. The lack of a documented relationship between increased internal levels of GSH and ac- cumulation of transcripts of sulfate transporters argues against GSH as a direct systemic regulator of sulfur metabolism (Buchner et al., 2004; Nocito et al., 2006; Rouached et al., 2008).

$O$-Acetylserine (OAS) is a direct precursor of Cys. In bacteria, OAS not only serves as a carbon/nitrogen skeleton for Cys synthesis, but it is also a positive regulatory molecule that directly binds to the CysB protein (a member of LysR family of transcription regulators), which activates transcription of genes that belong to the cysteine regulon (Kredich, 1992; 1996). Similarly, a strong influence of externally added OAS might suggest that this molecule serves as a positive factor of sulfur assimilation also in plants (Neuenschwander et al., 1991; Smith et al., 1997; Koprivova et al., 2000). It is also possible that OAS, which in normal conditions is the limiting substrate for cysteine synthesis, might function in plants as a sensor for an imbalance between sulfur and nitrogen metabolism (Hawkesford \& De Kok, 2006) and, as such, it might be rather a part of a regulatory network signaling a metabolic demand for sulfur-containing compounds (for example in the conditions of environmental stresses requiring increased level of GSH) than an element of a cascade signaling sulfur shortage in the soil. Nevertheless, a direct regulatory role of OAS is not as obvious in plants as it is in bacteria. Results of some experiments suggest that an increased level of OAS is rather a consequence of sulfur depletion than an early regulatory signal of sulfur shortage (Hopkins et al., 2005). On the other hand, a comparison of transcript profiles of A. thaliana in response to sulfur starvation or after OAS treatment revealed a large number of coregulated genes by both factors in either leaves or roots (Hirai et al., 2003). Interestingly, the same studies indicated a significant lack of coregulation of gene expression between leaves and roots of sulfur-deficient plants or between leaves and roots of plants grown in the presence of OAS. However, further analysis of gene expression using metabolite-to-gene network analysis indicated no apparent correlation of OAS accumulation with expression of genes known to be induced by sulfur deficit (Hirai et al., 2005). This further suggests that OAS may be only one of many signals (if not consequences) of sulfur deficiency in plants and, as mentioned above, that it is rather an element signaling the metabolic demand for sulfur than the status of sulfur nutrition available to the plant.

The mechanisms regulating gene expression in plants in response to sulfur shortage are not yet explained. It is not obvious why the external application of either GSH or OAS results in the changes of gene expression described above, 


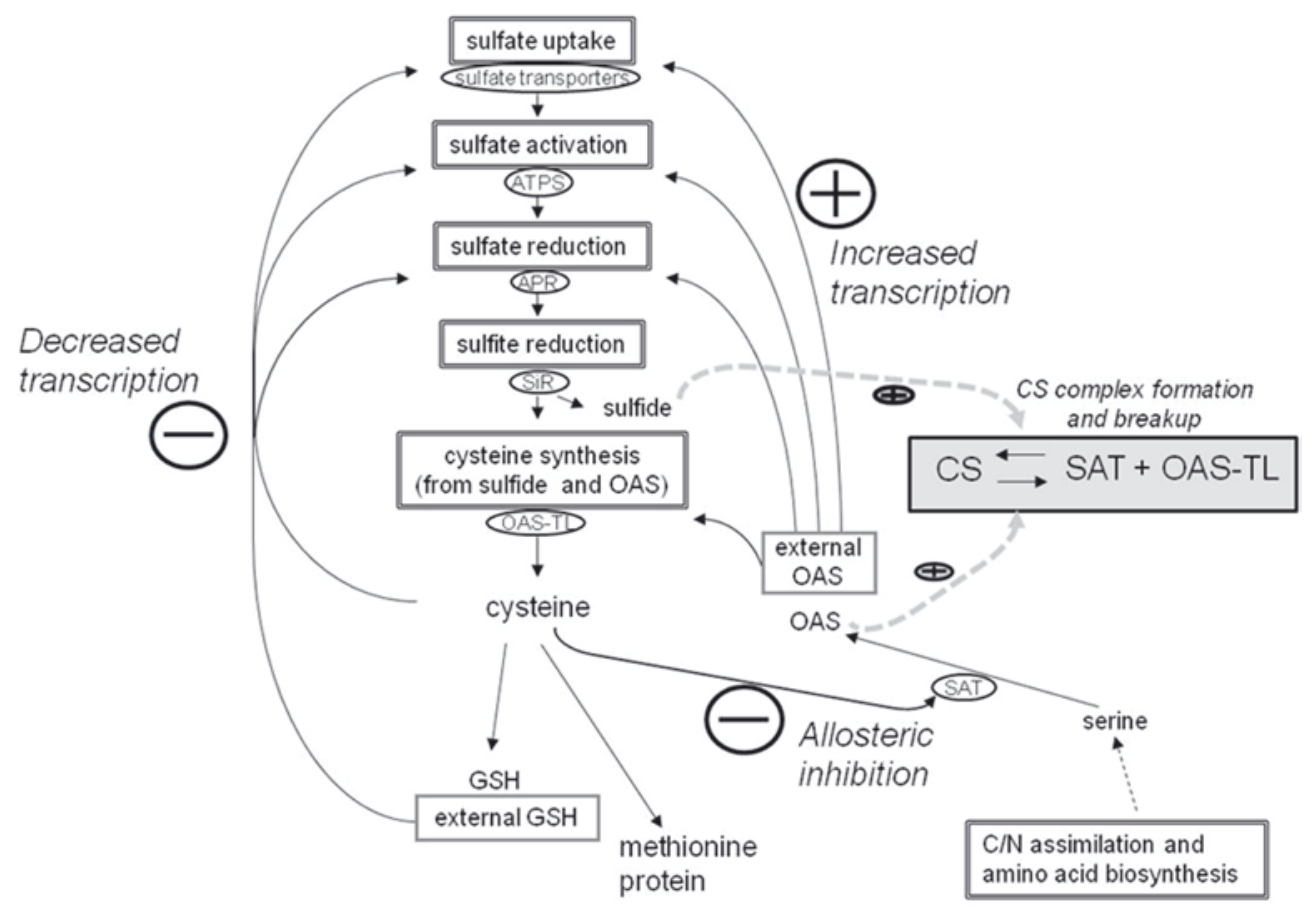

Figure 2. Metabolic control of sulfate uptake and assimilation by thiol-containing commpounds and OAS - modified from Hawkesford (2000).

A series of feedback loops repress or activate expression of genes encoding enzymes catalyzing some steps in the pathway. In addition, there is also feedback allosteric inhibition of SAT by cysteine and regulation of sulfur flux at the level of cysteine synthase (CS) complex. Sulfide stimulates complex formation, while OAS stimulates its dissociation; OAS-TL is inactive in the complex, while SAT is active only in the CS complex. ATPS, ATP sulfurylase; APR, APS reductase; SiR, sulfite reductase; OAS-TL, OAS (thiol)-lyase; SAT, serine acetyltransferase; GSH, glutathione; OAS, O-acetylserine. External GSH and external OAS refer to the compounds added to growth medium (see also explanations in the text).

while changes of the endogenous levels of these metabolites do not correlate with changes of the transcript levels. It is known that sulfate transport, reduction and further metabolism of sulfur in plants are controlled not only by availability of sulfate but also by metabolic demand for sulfurcontaining metabolites.

It has been proposed recently that these two partly overlapping regulatory mechanisms might be responsible for controlling gene expression, depending on whether the sulfur metabolism is stimulated by sulfur deficiency stress or by an internal metabolic demand (Rouached et al., 2008).

A scheme explaining the current understanding of the roles of OAS and thiol-containing compounds in the regulation of sulfur uptake and assimilation is shown in Fig. 2.

\section{Transcriptional control of plant responses to sulfur deficit}

Sequences named sulfur-responsive elements (SURE) containing 5-bp core sequences (GAGAC or GTCTC), which are very similar to the auxin response factor (ARF) binding sites, were identified in the promoter of SULTR1;1 gene of A. thaliana
(Maruyama-Nakashita et al., 2005) and occur in the promoter regions of many sulfur-responsive genes. The SURE element present in the promoter region of SULTR1;1 is in charge of transcriptional response to sulfur shortage but not to OAS and, what is very important, not to auxin (Maruyama-Nakashita et al., 2005). Nevertheless, it is possible that a not-yet-identified member of the ARF family of transcription factors (Guilfoyle \& Hagen, 2007) is capable of binding to SURE sequences and inducing sulfur deficiencydependent expression. The SURE sequences can also be found in promoters of genes not regulated by sulfur supply, therefore, additional regulatory factors must determine the specificity of the response to sulfur status.

The only so far identified trans-acting factor specifically regulating transcription of the genes involved in sulfate uptake and assimilation is SLIM1 (sulfur limitation 1), which was found during screening for mutation influencing the activity of the AtSULTR1;2 promoter in A. thaliana. SLIM1 appears to be identical to the transcription factor EIL3 (ethylene-insensitive3-like), a member of the EIL family (Maruyama-Nakashita et al., 2006). SLIM1/EIL3 plays an important role in response to sulfur starvation since its inactivation results in $60 \%$ 
limitation (in comparison to the wild type plants) of sulfate uptake under the conditions of sulfur deficit. Overexpression of SLIM1 in slim1 mutants restores the ability to respond to sulfur starvation. No other member of the EIL family of transcription factors is capable of reverting the slim 1 phenotype, which indicates that SLIM1/EIL3 is specialized for sulfur response. SLIM1 influences expression of many genes regulated by sulfur starvation, especially genes encoding sulfate transporters from groups 1, 3 and 4 , and enzymes from the glucosinolate metabolism pathway. Interestingly, the expression of some sulfur starvation-regulated genes, for example APR2 and $A P R 3$, is unaffected in the slim 1 mutant. In slim 1 mutants the levels of OAS and GSH are changed (increased and decreased, respectively) comparing to the wild type lines during sulfur starvation, but in the case of GSH only in the upper parts of the plants. The putative SLIM1 binding sites (AYGWAYCT) are not present in all sulfur starvation-induced genes with expression influenced by SLIM1. The information available so far suggests that (i) SLIM1 is located downstream in the regulatory cascade to the regulation of plant sulfur metabolism by OAS and GSH, (ii) SLIM1 influences only a part of the plant response to sulfur deprivation, (iii) SLIM1 is rather not the single trans-acting element of sulfur metabolism in plants and is probably an element of a complex signaling cascade.

Glucosinolates are sulfur-rich plant metabolites found almost exclusively in the Brassicaceae family containing well-known species such as Brassica oleracea (cabbage, cauliflower), B. rapa (turnip, Chinese cabbage), B. napus (rapeseed), Raphanus sativus (common radish), Armoracia rusticana (horseradish), A. thaliana, and many others. Degradation of glucosinolates is an important aspect of the sulfur limitation response in Brassicaceae since sulfur released from glucosinolates can be re-used in primary metabolism. SLIM1 co-regulates this sulfur recycling process by induction of genes encoding enzymes involved in glucosinolate degradation, and down-regulation of genes encoding enzymes needed for glucosinolate synthesis. Furthermore, it is known that sulfur deficiency represses the expression of three Myb transcription factors necessary for glucosinolate biosynthesis, PMG1/Myb28 and PMG1/Myb29 that are expressed preferentially in leaves and regulate biosynthesis of aliphatic glucosinolates, and ATR1/Myb34 expressed preferentially in roots and regulating biosynthesis of indole glucosinolates. The effect of SLIM1 on glucosinolate metabolism during sulfur shortage may be partially explained by its negative influence on ATR1/Myb34 expression in roots (Maruyama-Nakashita et al., 2006; Yan \& Chen, 2007). The role of SLIM1 in regulation of PMG1/
Myb28 and PMG1/Myb29 gene expression is unclear (Hirai et al., 2007).

$B I G$ is another gene from Arabidopsis reported as involved in the regulation of gene transcription under sulfur limitation (Kasajima et al., 2007). The BIG gene encodes a calossin-like protein necessary for the polar transport of auxin and it is, apparently, not a transcription factor. The BIG protein consists of 5098 amino acids and it has probably numerous functions. big mutants exhibit pleiotropic phenotypes suggesting defects in multiple processes such as sensing and/or signaling of hormones (e.g., auxin, cytokinin, giberellin, ethylene), light, and alterations of root architecture induced by phosphate deficiency. The significant increase of APR1 expression in optimal and -sulfur deficient conditions, and the slight increase of SULTR2;2 expression in optimal conditions in a big mutant in comparison to the control line suggest that BIG negatively influences transcription of these genes. The sulfate concentration and GSH level in this mutant seem not to be affected, while the mutation results in a decreased level of OAS in optimal sulfate supply (but not during sulfur deficit). These observations suggest that either BIG has an influence on the signal transduction pathway independently from the OAS/GSH regulation or it is downstream of OAS/GSH in the signal cascade. Experiments with plants treated with auxin or with a polar auxin transport inhibitor imply that the induction of sulfur deficit-responding genes in the big mutant is rather independent of auxin (Kasajima et al., 2007).

Recently, the influence of three sulfur starvation-responsive transcription factors, IAA13, IAA28 and ARF-2, on the sulfate assimilation pathway in A. thaliana has been studied (Falkenberg et al., 2008). The authors investigated both overexpressing and knock-down lines under normal and sulfate deficiency conditions and they observed pleiotropic effects of these mutations. The main conclusion of the reported work was that the studied factors serve as coordinators of the metabolic shift driving sulfur homeostasis rather than as direct effectors of the sulfate assimilation pathway.

\section{Regulation by miRNA}

Controlling the level of gene expression by miRNA-initiated cleavage of cognate complementary mRNAs has significant regulatory function. miRNAs are not only involved in developmental processes but also in response to biotic and abiotic stress, including oxidative stresses and deprivation of nutrients, such as phosphate or sulfate (Sunkar et al., 2007). miRNA395, represented by six loci arranged in two clusters, is induced by sulfur limitation in $A$. thaliana. Targets for this miRNA are genes encoding 
ATP sulfurylases (APS1, APS3, APS4), sulfate transporter (AtSULTR2;1) implicated in the internal translocation of sulfate from roots to shoots, and possibly other genes (Jones-Rhoades \& Bartel, 2004; Adai et al., 2005; Allen et al., 2005). Influence on two gene families (APRs and SULTRs) encoding proteins that function coordinately in the same metabolic pathway is an unusual example for a function of plant miRNA. Despite the fact that an important role for miRNA395 in regulating sulfate homeostasis seems to be obvious, the functional significance of this regulation still needs to be investigated (Sunkar et al., 2007).

\section{Post-translational regulation and involvement of protein kinases}

Some high affinity sulfate transporters are apparently regulated on the post-translational level (Yoshimoto et al., 2007). They contain a conserved region named STAS (sulfate transporter and antisigma factor antagonist) domain at their C-terminus. The STAS domain shares significant similarity with the Bacillus sp. anti-sigma factor antagonist SpoIIAA, and is suggested to function as a domain for protein-protein interactions, which may play a role in regulating the activity and/or stability of sulfate transporters. Experiments performed with SULTR1;1 and SULTR1;2 have revealed that this domain is key for the activity and stability of the transporters, while a linking region containing several amino acids is critical for functioning of the protein. Also phosphorylation of STAS domain regulates the activity of SULTR1;2 (Shibagaki \& Grossman, 2004; 2006; Rouached et al., 2005).

Two enzymes involved in sulfur metabolism, APS reductase and glutamate-cysteine ligase ( $\gamma$-glutamylcysteine synthase), can be activated by oxidation resulting in the formation of intramolecular disulfide bonds, which influences assimilation of sulfate and GSH level, respectively, in response to the redox status of the cell (Bick et al., 2001; Hicks et al., 2007).

The SAT enzyme can be subject to feedback allosteric regulation by cysteine. Different SAT isoforms have different sensitivity towards such feedback regulation: the isoforms localized in organelles in Arabidopsis and watermelon are feedback-insensitive, while the cytosolic ones are feedback-sensitive (Noji et al., 1998). Moreover, in Glycine max the activity of at least one SAT isoform (GmSerat2;1) can be modified by calcium-dependent protein kinase (Liu et al., 2006). The phosphorylation of GmSerat2;1 occurring under oxidative stress converts this SAT to a form insensitive to feedback inhibition by cysteine. This allows to increase cysteine production and to further support production of glutathione that is im- portant in response to stresses. However, analysis of plant SAT sequences available in data bases for the presence of potential phosphorylation sites does not suggest that phosphorylation of SAT may be a universal mechanism (Liu et al., 2006).

Recently, it has been shown that a member of the plant-specific SNRK2 kinase family acts as a key regulator in the signaling cascade of the sulfur deprivation response in Chlamydomonas reihardtii (Gonzalez-Ballester et al., 2008). Some limited data exist that allow one to speculate that the SNRK2 type kinases are involved in regulation of the sulfur metabolism pathway also in higher plants. For example, mutation of the SNRK2.3 gene of A. thaliana resulted in reduced induction of SULTR2;2 during sulfur deficit, while the accumulation of OAS was higher than that in wild type plants grown in the same conditions (Kimura et al., 2006). However, an unchanged expression of other sulfur nutrition-responsive genes $(A P R$ and $S A T)$ in the snrk2.3 mutant suggests rather a moderate role of this kinase in regulation of the sulfur pathway.

Control of sulfur flux by formation of the cysteine synthase complex affecting SAT and OAS-TL activities

The last steps of cysteine biosynthesis are catalyzed by a bi-enzyme complex, called cysteine synthase (CS), which is composed of a dimer of homotrimers of serine acetyltransferase (SAT) and two homodimers of $\mathrm{O}$-acetylserine (thiol)-lyase (OAS$\mathrm{TL})$. Formation of the CS complex plays an important role in the regulation of both enzymatic activities. OASTL is active only in a free form, while SAT activity is dependent on the association with OASTL (Droux et al., 1998; Wirtz \& Hell, 2007). Sulfide stimulates the formation of the complex, while OAS stimulates its dissociation (Fig. 2). The tertiary structures of bacterial SAT and of OAS-TL from bacteria and plants are known (Burkhard et al., 1998; Tai et al., 2001; Hindson \& Shaw, 2003; Gorman \& Shapiro, 2004; Olsen et al., 2004; Pye et al., 2004; Bonner et al., 2005). No crystal structure of a full CS complex is available yet, however, on the basis of the recently determined tertiary structure of OAS-TL with the C-terminal decapeptide of SAT (Huang et al., 2005; Francois et al., 2006) and the fluorescence spectroscopy data for the OAS-TL-SAT mixture (Campanini et al., 2003) it is assumed that SAT binds to OASTL from its catalytic cavity side. The substrate, OAS, binds to OAS-TL also at the catalytic cavity, thus the interaction of OAS-TL with SAT appears to effectively inhibit the activity of the former enzyme.

The formation of the CS complexes appears to control cysteine synthesis including the flux through the entire assimilatory pathway. In plants the situ- 
ation is additionally complicated by the subcellular compartmentalization of isoforms of both enzymes and the complexes, which may serve different purposes and may be differentially regulated in each compartment. It was recently demonstrated that the disruption of CS complex formation due to production of enzymatically inactive SAT (but capable of interaction with OAS-TL) in the cytosol of transgenic tobacco plants resulted in deregulation of not only the cytosol CS complex but also of the organellar CS complexes and strongly increased accumulation of Cys and GSH (Wirtz \& Hell, 2007). Furthermore, analysis of knock-out mutants of the major OASTL isoforms in A. thaliana has shown that, surprisingly, mitochondria play the most important role for cysteine synthesis in this plant despite that both sulfide and cysteine can be efficiently exchanged between cytosol and organelles (Heeg et al., 2008).

For examples of the effects of modification of SAT and OAS-TL levels in plants and for a model explaining the significance of CS complex formation the reader is referred to other reviews (Hell \& Hillebrand, 2001; Sirko et al., 2004; Wirtz \& Droux, 2005).

\section{SULFUR FLUX AS PART OF GENERAL PLANT METABOLISM - ELUCIDATION OF PLANT RESPONSE TO SULFUR DEFICIT USING SYSTEMS BIOLOGY APPROACH}

Sulfur metabolism cannot be separated from the general plant metabolism, and it is strongly influenced by such factors as availability of other nutrients (nitrogen, phosphorus), carbohydrate metabolism, and light. Expression of many genes of the pathway, including APS reductase (APR), sulfite reductase and chloroplastic isoforms of OAS-TL undergo diurnal rhythm. Besides, it has been demonstrated that addition of sucrose to the medium after treatment with darkness induces APR activity in roots (Koprivova et al., 2000; Kopriva \& Koprivova, 2003). The reductive assimilation pathway of nitrate and sulfate are linked through the availability of electrons and pools of carbohydrates, which fluctuate diurnally. Both metabolic pathways are very well coordinated and depletion of one element represses the other pathway (Koprivova et al., 2000; Migge et al., 2000; Prosser et al., 2001; Hesse et al., 2004).

Taking into account the multiple interactions between sulfur metabolism and other metabolic pathways it should not be surprising that numerous transcriptomic and metabolomic changes are induced in plants by sulfur deprivation. It has been shown in tobacco that even a shortterm sulfur deficit influences expression of numerous genes from different functional categories, including those involved in stress- and pathogen response, formation of cell-wall structure, protein degradation, photosynthesis, carbon metabolism, translation and, of course, sulfur metabolism (Maruyama-Nakashita et al., 2003; Nikiforova et al., 2003; Lewandowska et al., 2005; Wawrzynska et al., 2005). The possibility of using macro- and microarrays of $A$. thaliana covering almost the complete genome has facilitated the analysis of transcriptional changes under sulfur starvation in this model plant (Hirai et al., 2003). The molecular and metabolic changes in plants that encounter sulfur shortage were recently arranged in an interesting schema depicting the sequence of events (Hawkesford \& De Kok, 2006). It has been proposed that plant responses to sulfur starvation can be divided into three major phases depending on the degree and duration of sulfur deficit (Fig. 3A). During the initial phase, changes in expression concern predominantly genes from the sulfur assimilation pathway, sulfate uptake and remobilization of inorganic sulfur reserves from the vacuole. After this phase, when sulfur is still a limiting factor, changes involve multiple metabolic pathways. Plants intensify the turnover of organic sulfur, initiate stress defense response and down-regulate genes responsible for the uptake and assimilation of nitrogen. This phase is followed by changes in developmental processes such as increase of rootto-shoot mass ratio, induction of senescence and, at the end, growth deprivation of both shoots and roots and starting of earlier reproduction to save the sulfur resources for production of vital seeds. Long-term sulfur starvation causes a decrease in the level of total proteins, chlorophyll, RNA and biomass. One of the visual symptoms of sulfur shortage is chlorosis occurring mainly in young leaves which produce insufficient amounts of chlorophyll and lipids which in turn leads to reduction of photosynthetic activity and an overall decline of metabolism.

Integration of data from transcriptomic and metabolomic studies from various periods of sulfur deprivation has revealed a complexity of the plant response to a gradually progressing reduction of sulfur availability (Hirai \& Saito, 2004; Nikiforova et al., 2004; 2005a; 2005b; Noctor, 2006). A compiled model proposing the existence of two states, the state of sulfur limitation (short-term response) and the state of sulfur deficiency (long-term response) has been proposed recently (Hoefgen \& Nikiforova, 2008). According to this model, which is schematically shown in Fig. 3B, auxin is implicated in the physiological changes during short-term response. Plant metabolism is directed towards intensification of sulfate uptake and assimilation, and sulfur mobilization from various resources. Although no evidence from direct 
A

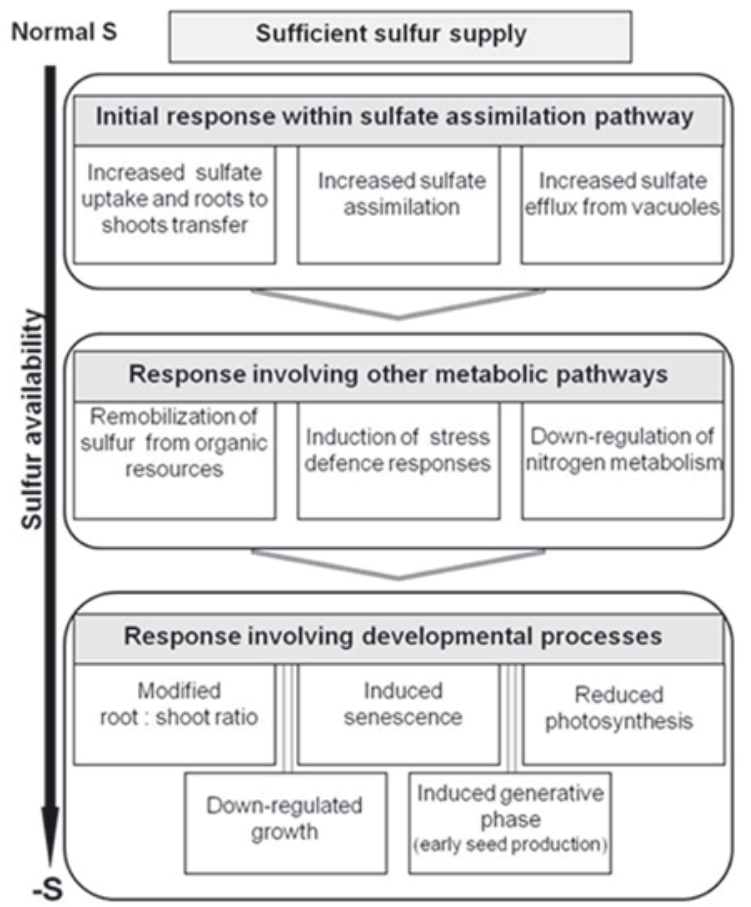

B

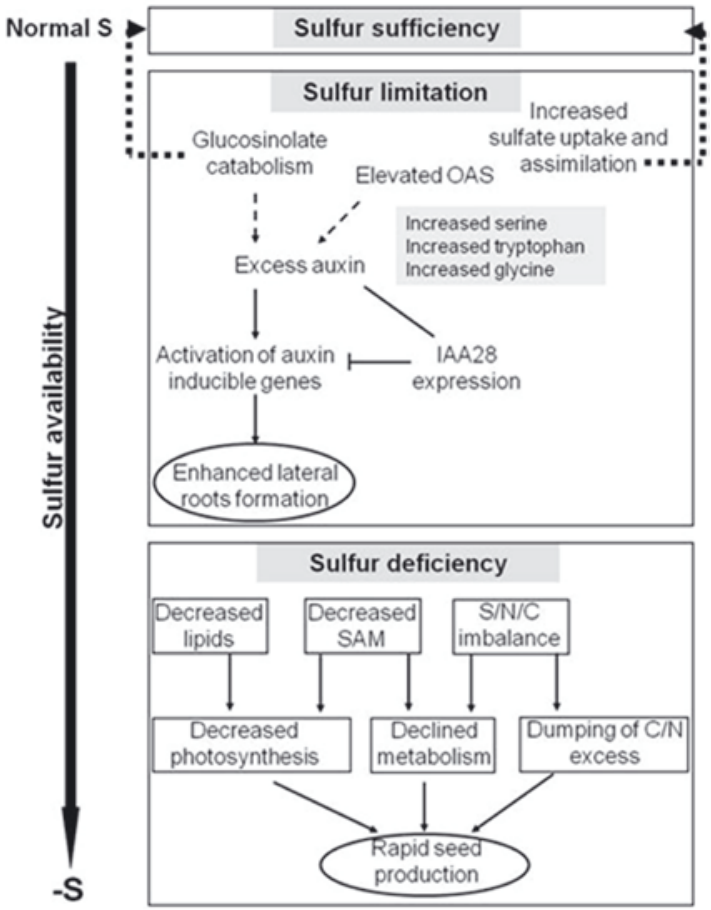

Figure 3. Models of the sequence of events in plants grown at insufficient sulfur supply (-S).

The model A is adapted from Hawkesford and De Kok (2006) and the model B is adapted from Hoefgen \& Nikiforova (2008).

measurements of auxin level exist, the presumably elevated auxin level triggers enhanced production of lateral roots (in search of sulfur resources). In the case of a prolonged period of sulfur starvation, the next state defined as sulfur deficiency is observed in plants. The factors influencing the transition between these two states are poorly understood, however, it is proposed that the feedback inhibition of auxin-induced genes by transcriptional regulator IAA28 (see also above) might be responsible for such a switch. Decreased SAM and lipid levels, reduced photosynthesis and misbalanced sulfur/nitrogen/carbon metabolism lead toward an overall decline of metabolism, growth inhibition, rescue reprogramming of the life cycle and premature seed production.

In conclusion, despite our knowledge of the regulatory mechanisms responsible for the plant response to sulfur availability having advanced significantly, mostly due to application of modern high-throughput and systems biology approaches, full understanding of the process requires numerous questions to be answered.

\section{Acknowledgements}

Research in our laboratory is supported by grants from the Ministry of Education and Science, Poland (SPB/ COST/112/2005 and N N302 119435).

\section{REFERENCES}

Adai A, Johnson C, Mlotshwa S, Archer-Evans S, Manocha V, Vance V, Sundaresan V (2005) Computational prediction of miRNAs in Arabidopsis thaliana. Genome Res 15: 78-91.

Allen E, Xie Z, Gustafson AM, Carrington JC (2005) microRNA-directed phasing during trans-acting siRNA biogenesis in plants. Cell 121: 207-221.

Bick JA, Setterdahl AT, Knaff DB, Chen Y, Pitcher LH, Zilinskas BA, Leustek T (2001) Regulation of the planttype 5 -adenylyl sulfate reductase by oxidative stress. Biochemistry 40: 9040-9048.

Blaszczyk A, Brodzik R, Sirko A (1999) Increased resistance to oxidative stress in transgenic tobacco plants overexpressing bacterial serine acetyltransferase. Plant J 20: 237-243.

Bolchi A, Petrucco S, Tenca PL, Foroni C, Ottonello S (1999) Coordinate modulation of maize sulfate permease and ATP sulfurylase mRNAs in response to variations in sulfur nutritional status: stereospecific down-regulation by L-cysteine. Plant Mol Biol 39: 527-537.

Bonner ER, Cahoon RE, Knapke SM, Jez JM (2005) Molecular basis of cysteine biosynthesis in plants: structural and functional analysis of $\mathrm{O}$-acetylserine sulfhydrylase from Arabidopsis thaliana. J Biol Chem 280: 38803-38813.

Bourgis F, Roje S, Nuccio ML, Fisher DB, Tarczynski MC, Li C, Herschbach C, Rennenberg H, Pimenta MJ, Shen TL, Gage DA, Hanson AD (1999) S-Methylmethionine plays a major role in phloem sulfur transport and is synthesized by a novel type of methyltransferase. Plant Cell 11: 1485-1498. 
Buchner P, Stuiver CE, Westerman S, Wirtz M, Hell R, Hawkesford MJ, De Kok LJ (2004) Regulation of sulfate uptake and expression of sulfate transporter genes in Brassica oleracea as affected by atmospheric $\mathrm{H}_{2} \mathrm{~S}$ and pedospheric sulfate nutrition. Plant Physiol 136: 3396 3408.

Burkhard P, Rao GS, Hohenester E, Schnackerz KD, Cook PF, Jansonius JN (1998) Three-dimensional structure of $\mathrm{O}$-acetylserine sulfhydrylase from Salmonella typhimurium. J Mol Biol 283: 121-133.

Campanini B, Raboni S, Vaccari S, Zhang L, Cook PF, Hazlett TL, Mozzarelli A, Bettati S (2003) Surface-exposed tryptophan residues are essential for O-acetylserine sulfhydrylase structure, function, and stability. $J$ Biol Chem 278: 37511-37519.

Droux M (2004) Sulfur assimilation and the role of sulfur in plant metabolism: a survey. Photosynth Res 79: 331348.

Droux M, Ruffet ML, Douce R, Job D (1998) Interactions between serine acetyltransferase and O-acetylserine (thiol) lyase in higher plants-structural and kinetic properties of the free and bound enzymes. Eur I Biochem 255: 235-245.

El Kassis E, Cathala N, Rouached H, Fourcroy P, Berthomieu P, Terry N, Davidian JC (2007) Characterization of a selenate-resistant Arabidopsis mutant. Root growth as a potential target for selenate toxicity. Plant Physiol 143: 1231-1241.

Falkenberg B, Witt I, Zanor MI, Steinhauser D, MuellerRoeber B, Hesse H, Hoefgen R (2008) Transcription factors relevant to auxin signalling coordinate broadspectrum metabolic shifts including sulphur metabolism. J Exp Bot 59: 2831-2846.

Fontecave M, Atta M, Mulliez E (2004) S-Adenosylmethionine: nothing goes to waste. Trends Biochem Sci 29: 243-249.

Foyer CH, Noctor G (2005) Redox homeostasis and antioxidant signaling: a metabolic interface between stress perception and physiological responses. Plant Cell 17: 1866-1875.

Francois JA, Kumaran S, Jez JM (2006) Structural basis for interaction of $\mathrm{O}$-acetylserine sulfhydrylase and serine acetyltransferase in the Arabidopsis cysteine synthase complex. Plant Cell 18: 3647-3655.

Giordano M, Norici A, Hell R (2005) Sulfur and phytoplankton: acquisition, metabolism and impact on the environment. New Phytol 166: 371-382.

Gonzalez-Ballester D, Pollock SV, Pootakham W, Grossman AR (2008) The central role of a SNRK2 kinase in sulfur deprivation responses. Plant Physiol 147: 216-227.

Gorman J, Shapiro L (2004) Structure of serine acetyltransferase from Haemophilus influenzae Rd. Acta Crystallogr D Biol Crystallogr 60: 1600-1605.

Granvogl M, Wieser H, Koehler P, Tucher SV, Schieberle P (2007) Influence of sulfur fertilization on the amounts of free amino acids in wheat. correlation with baking properties as well as with 3-aminopropionamide and acrylamide generation during baking. J Agric Food Chem 55: 4271-4277.

Grimble RF (1994) Sulphur amino acids and the metabolic response to cytokines. Adv Exp Med Biol 359: 41-49.

Guilfoyle TJ, Hagen G (2007) Auxin response factors. Curr Opin Plant Biol 10: 453-460.

Hansch R, Lang C, Rennenberg H, Mendel RR (2007) Significance of plant sulfite oxidase. Plant Biol 9: 589-595.

Harms K, von Ballmoos P, Brunold C, Hofgen R, Hesse H (2000) Expression of a bacterial serine acetyltransferase in transgenic potato plants leads to increased levels of cysteine and glutathione. Plant J 22: 335-343.
Hawkesford MJ (2000) Plant responses to sulphur deficiency and the genetic manipulation of sulphate transporters to improve S-utilization efficiency. J Exp Bot 51: 131-138.

Hawkesford MJ (2003) Transporter gene families in plants: the sulphate transporter gene family - redundancy or specialization? Physiol Plant 117: 155-163.

Hawkesford MJ, De Kok LJ (2006) Managing sulphur metabolism in plants. Plant Cell Environ 29: 382-395.

Heeg C, Kruse C, Jost R, Gutensohn M, Ruppert T, Wirtz M, Hell R (2008) Analysis of the Arabidopsis $O$-acetylserine(thiol)lyase gene family demonstrates compartment-specific differences in the regulation of cysteine synthesis. Plant Cell 20: 168-185.

Hell R, Hillebrand H (2001) Plant concepts for mineral acquisition and allocation. Curr Opin Biotechnol 12: 161168.

Herschbach C, van Der Zalm E, Schneider A, Jouanin L, De Kok LJ, Rennenberg H (2000) Regulation of sulfur nutrition in wild-type and transgenic poplar over-expressing gamma-glutamylcysteine synthetase in the cytosol as affected by atmospheric $\mathrm{H}_{2} \mathrm{~S}$. Plant Physiol 124: 461-473.

Hesse H, Nikiforova V, Gakiere B, Hoefgen R (2004) Molecular analysis and control of cysteine biosynthesis: integration of nitrogen and sulphur metabolism. J Exp Bot 55: 1283-1292.

Hicks LM, Cahoon RE, Bonner ER, Rivard RS, Sheffield J, Jez JM (2007) Thiol-based regulation of redox-active glutamate-cysteine ligase from Arabidopsis thaliana. Plant Cell 19: 2653-2661.

Hindson VJ, Shaw WV (2003) Random-order ternary complex reaction mechanism of serine acetyltransferase from Escherichia coli. Biochemistry 42: 3113-3119.

Hirai MY, Saito K (2004) Post-genomics approaches for the elucidation of plant adaptive mechanisms to sulphur deficiency. J Exp Bot 55: 1871-1879.

Hirai MY, Fujiwara T, Awazuhara M, Kimura T, Noji M, Saito K (2003) Global expression profiling of sulfurstarved Arabidopsis by DNA macroarray reveals the role of $O$-acetyl-L-serine as a general regulator of gene expression in response to sulfur nutrition. Plant $J$ 33: 651-663.

Hirai MY, Klein M, Fujikawa Y, Yano M, Goodenowe DB, Yamazaki Y, Kanaya S, Nakamura Y, Kitayama M, Suzuki H, Sakurai N, Shibata D, Tokuhisa J, Reichelt M, Gershenzon J, Papenbrock J, Saito K (2005) Elucidation of gene-to-gene and metabolite-to-gene networks in Arabidopsis by integration of metabolomics and transcriptomics. J Biol Chem 280: 25590-25595.

Hirai MY, Sugiyama K, Sawada Y, Tohge T, Obayashi T, Suzuki A, Araki R, Sakurai N, Suzuki H, Aoki K, Goda H, Nishizawa OI, Shibata D, Saito K (2007) Omics-based identification of Arabidopsis Myb transcription factors regulating aliphatic glucosinolate biosynthesis. Proc Natl Acad Sci USA 104: 6478-6483.

Hoefgen R, Nikiforova VJ (2008) Metabolomics integrated with transcriptomics: assessing systems response to sulfur-deficiency stress. Physiol Plant 132: 190-198.

Hopkins L, Parmar S, Blaszczyk A, Hesse H, Hoefgen R, Hawkesford MJ (2005) O-Acetylserine and the regulation of expression of genes encoding components for sulfate uptake and assimilation in potato. Plant Physiol 138: $433-440$.

Huang B, Vetting MW, Roderick SL (2005) The active site of $\mathrm{O}$-acetylserine sulfhydrylase is the anchor point for bienzyme complex formation with serine acetyltransferase. J Bacteriol 187: 3201-3205. 
Hunter EA, Grimble RF (1997) Dietary sulphur amino acid adequacy influences glutathione synthesis and glutathione-dependent enzymes during the inflammatory response to endotoxin and tumour necrosis factor-alpha in rats. Clin Sci (Lond) 92: 297-305.

Jones-Rhoades MW, Bartel DP (2004) Computational identification of plant microRNAs and their targets, including a stress-induced miRNA. Mol Cell 14: 787-799.

Kasajima I, Ohkama-Ohtsu N, Ide Y, Hayashi H, Yoneyama T, Suzuki Y, Naito S, Fujiwara T (2007) The BIG gene is involved in regulation of sulfur deficiency-responsive genes in Arabidopsis thaliana. Physiol Plant 129: 351-363.

Kimura T, Shibagaki N, Ohkama-Ohtsu N, Hayashi H, Yoneyama T, Davies JP, Fujiwara T (2006) Arabidopsis SNRK2.3 protein kinase is involved in the regulation of sulfur-responsive gene expression and O-acetyl-L-serine accumulation under limited sulfur supply. Soil Sci Plant Nutr 52: 211-220.

Klein M, Papenbrock J (2004) The multi-protein family of Arabidopsis sulphotransferases and their relatives in other plant species. J Exp Bot 55: 1809-1820.

Knop M, Pacyna S, Voloshchuk N, Kant S, Mullenborn C, Steiner U, Kirchmair M, Scherer HW, Schulz M (2007) Zea mays: benzoxazolinone detoxification under sulfur deficiency conditions - a complex allelopathic alliance including endophytic Fusarium verticillioides. I Chem Ecol 33: 225-237.

Komarnisky LA, Christopherson RJ, Basu TK (2003) Sulfur: its clinical and toxicologic aspects. Nutrition 19: 54-61.

Kopriva S (2006) Regulation of sulfate assimilation in Arabidopsis and beyond. Ann Bot 97: 479-495.

Kopriva S, Koprivova A (2003) Sulphate assimilation: a pathway which likes to surprise. In Sulphur in Higher Plants. Abrol YP, Ahmad A, eds, pp 87-112. Kluwer Academic Publishers, Dordrecht.

Kopriva S, Wiedemann G, Reski R (2007) Sulfate assimilation in basal land plants - what does genomic sequencing tell us? Plant Biol 9: 556-564.

Koprivova A, Suter M, den Camp RO, Brunold C, Kopriva S (2000) Regulation of sulfate assimilation by nitrogen in Arabidopsis. Plant Physiol 122: 737-746.

Koprivova A, Meyer AJ, Schween G, Herschbach C, Reski R, Kopriva S (2002) Functional knockout of the adenosine 5'-phosphosulfate reductase gene in Physcomitrella patens revives an old route of sulfate assimilation. J Biol Chem 277: 32195-32201.

Kredich NM (1992) The molecular basis for positive regulation of cys promoters in Salmonella typhimurium and Escherichia coli. Mol Microbiol 6: 2747-2753.

Kredich NM (1996) Biosynthesis of cysteine. In Escherichia coli and Salmonell typhimurium. Neidhardt FC, Curtiss $\mathrm{R}$, Ingraham JL, Linn ECC, Low KB, Magasanik B, Reznikoff WS, Riley M, Schaechter M, Umberger M, eds. Cellular and Molecular Biology, pp 514-752. ASM Press, Washington DC.

Kruse C, Jost R, Lipschis M, Kopp B, Hartmann M, Hell R (2007) Sulfur-enhanced defence: effects of sulfur metabolism, nitrogen supply, and pathogen lifestyle. Plant Biol 9: 608-619.

Lang C, Popko J, Wirtz M, Hell R, Herschbach C, Kreuzwieser J, Rennenberg H, Mendel RR, Hansch R (2007) Sulphite oxidase as key enzyme for protecting plants against sulphur dioxide. Plant Cell Environ 30: 447-455.

Lappartient AG, Touraine B (1996) Demand-driven control of root ATP sulfurylase activity and $\mathrm{SO}_{4}{ }^{2-}$ uptake in intact canola (the role of phloem-translocated glutathione). Plant Physiol 111: 147-157.
Lappartient AG, Vidmar JJ, Leustek T, Glass AD, Touraine B (1999) Inter-organ signaling in plants: regulation of ATP sulfurylase and sulfate transporter genes expression in roots mediated by phloem-translocated compound. Plant J 18: 89-95.

Leustek T (2002) Sulfate metabolism. In The Arabidopsis Book. Somerville CR, Meyerowitz EM, eds, American Society of Plant Biologists, Rockville, MD, doi: 10.1199/ tab.0009, www.aspb.org/publications/arabidopsis/.

Lewandowska M, Wawrzynska A, Kaminska J, Liszewska F, Sirko A (2005) Identification of novel proteins of Nicotiana tabacum regulated by short term sulfur starvation. In Sulfur Transport and Assimilation in Plants in the Postgenomic Era. Saito K, De Kok LJ, Stuhlen I, Hawkesford MJ, Schnug E, Sirko A, Rennenberg H, eds, pp 153-156. Backhuys Publishers, Leiden, The Netherlands.

Liu F, Yoo BC, Lee JY, Pan W, Harmon AC (2006) Calcium-regulated phosphorylation of soybean serine acetyltransferase in response to oxidative stress. J Biol Chem 281: 27405-27415.

Marshner H (2005) Mineral Nutrition of Higher Plants. Second edition. Elsevier Academic Press, London, UK.

Maruyama-Nakashita A, Inoue E, Watanabe-Takahashi A, Yamaya T, Takahashi H (2003) Transcriptome profiling of sulfur-responsive genes in Arabidopsis reveals global effects of sulfur nutrition on multiple metabolic pathways. Plant Physiol 132: 597-605.

Maruyama-Nakashita A, Nakamura Y, Watanabe-Takahashi A, Inoue E, Yamaya T, Takahashi H (2005) Identification of a novel cis-acting element conferring sulfur deficiency response in Arabidopsis roots. Plant J 42: 305-314.

Maruyama-Nakashita A, Nakamura Y, Tohge T, Saito K, Takahashi H (2006) Arabidopsis SLIM1 is a central transcriptional regulator of plant sulfur response and metabolism. Plant Cell 18: 3235-3251.

Migge A, Bork C, Hell R, Becker TW (2000) Negative regulation of nitrate reductase gene expression by glutamine or asparagine accumulating in leaves of sulfur-deprived tobacco. Planta 211: 587-595.

Muttucumaru N, Halford NG, Elmore JS, Dodson AT, Parry M, Shewry PR, Mottram DS (2006) Formation of high levels of acrylamide during the processing of flour derived from sulfate-deprived wheat. J Agric Food Chem 54: 8951-8955.

Neuenschwander U, Suter M, Brunold C (1991) Regulation of sulfate assimilation by light and $O$-acetyl-L-serine in Lemna minor L. Plant Physiol 97: 253-258.

Nikiforova V, Freitag J, Kempa S, Adamik M, Hesse H, Hoefgen R (2003) Transcriptome analysis of sulfur depletion in Arabidopsis thaliana: interlacing of biosynthetic pathways provides response specificity. Plant $J$ 33: 633-650.

Nikiforova VJ, Gakiere B, Kempa S, Adamik M, Willmitzer L, Hesse H, Hoefgen R (2004) Towards dissecting nutrient metabolism in plants: a systems biology case study on sulphur metabolism. J Exp Bot 55: 1861-1870.

Nikiforova VJ, Daub CO, Hesse H, Willmitzer L, Hoefgen $R$ (2005a) Integrative gene-metabolite network with implemented causality deciphers informational fluxes of sulphur stress response. J Exp Bot 56: 1887-1896.

Nikiforova VJ, Kopka J, Tolstikov V, Fiehn O, Hopkins L, Hawkesford MJ, Hesse H, Hoefgen R (2005b) Systems rebalancing of metabolism in response to sulfur deprivation, as revealed by metabolome analysis of Arabidopsis plants. Plant Physiol 138: 304-318. 
Nocito FF, Lancilli C, Crema B, Fourcroy P, Davidian JC, Sacchi GA (2006) Heavy metal stress and sulfate uptake in maize roots. Plant Physiol 141: 1138-1148.

Noctor G (2006) Metabolic signalling in defence and stress: the central roles of soluble redox couples. Plant Cell Environ 29: 409-425.

Noji M, Inoue K, Kimura N, Gouda A, Saito K (1998) Isoform-dependent differences in feedback regulation and subcellular localization of serine acetyltransferase involved in cysteine biosynthesis from Arabidopsis thaliana. J Biol Chem 273: 32739-32745.

Norici A, Hell R, Giordano M (2005) Sulfur and primary production in aquatic environments: an ecological perspective. Photosynth Res 86: 409-417.

Olsen LR, Huang B, Vetting MW, Roderick SL (2004) Structure of serine acetyltransferase in complexes with CoA and its cysteine feedback inhibitor. Biochemistry 43: 6013-6019.

Papenbrock J, Riemenschneider A, Kamp A, Schulz-Vogt HN, Schmidt A (2007) Characterization of cysteine-degrading and $\mathrm{H}_{2} \mathrm{~S}$-releasing enzymes of higher plants - from the field to the test tube and back. Plant Biol 9: $582-588$.

Prosser IM, Purves JV, Saker LR, Clarkson DT (2001) Rapid disruption of nitrogen metabolism and nitrate transport in spinach plants deprived of sulphate. J Exp Bot 52: 113-121.

Pye VE, Tingey AP, Robson RL, Moody PC (2004) The structure and mechanism of serine acetyltransferase from Escherichia coli. J Biol Chem 279: 40729-40736.

Rausch T, Wachter A (2005) Sulfur metabolism: a versatile platform for launching defence operations. Trends Plant Sci 10: 503-509.

Rennenberg H, Schmitz K, Bergmann L (1979) Long-distance transport of sulfur in Nicotiana tabacum. Planta 147: 57-62.

Riemenschneider A, Riedel K, Hoefgen R, Papenbrock J, Hesse H (2005a) Impact of reduced Oacetylserine(thiol)lyase isoform contents on potato plant metabolism. Plant Physiol 137: 892-900.

Riemenschneider A, Wegele R, Schmidt A, Papenbrock J (2005b) Isolation and characterization of a D-cysteine desulfhydrase protein from Arabidopsis thaliana. FEBS J 272: 1291-1304.

Roje S (2006) S-Adenosyl-L-methionine: beyond the universal methyl group donor. Phytochemistry 67: 1686-1698.

Rouached H, Berthomieu P, El Kassis E, Cathala N, Catherinot V, Labesse G, Davidian JC, Fourcroy P (2005) Structural and functional analysis of the C-terminal STAS (sulfate transporter and anti-sigma antagonist) domain of the Arabidopsis thaliana sulfate transporter SULTR1.2. J Biol Chem 280: 15976-15983.

Rouached H, Wirtz M, Alary R, Hell R, Arpat AB, Davidian JC, Fourcroy P, Berthomieu P (2008) Differential regulation of the expression of two high-affinity sulfate transporters, SULTR1.1 and SULTR1.2, in Arabidopsis. Plant Physiol 147: 897-911.

Saito K (2004) Sulfur assimilatory metabolism. The long and smelling road. Plant Physiol 136: 2443-2450.

Scherer HW (2001) Sulphur in crop production - invited paper. Eur J Agron 14: 81-111.

Sekine K, Fujiwara M, Nakayama M, Takao T, Hase T, Sato N (2007) DNA binding and partial nucleoid localization of the chloroplast stromal enzyme ferredoxin: sulfite reductase. FEBS J 274: 2054-2069.

Shibagaki N, Grossman AR (2004) Probing the function of STAS domains of the Arabidopsis sulfate transporters. J Biol Chem 279: 30791-30799.
Shibagaki N, Grossman AR (2006) The role of the STAS domain in the function and biogenesis of a sulfate transporter as probed by random mutagenesis. J Biol Chem 281: 22964-22973.

Sirko A, Blaszczyk A, Liszewska F (2004) Overproduction of SAT and/or OASTL in transgenic plants: a survey of effects. J Exp Bot 55: 1881-1888.

Smith FW, Hawkesford MJ, Ealing PM, Clarkson DT, Vanden Berg PJ, Belcher AR, Warrilow AG (1997) Regulation of expression of a cDNA from barley roots encoding a high affinity sulphate transporter. Plant $J$ 12: 875-884.

Sunkar R, Chinnusamy V, Zhu J, Zhu JK (2007) Small RNAs as big players in plant abiotic stress responses and nutrient deprivation. Trends Plant Sci 12: 301-309.

Tai CH, Burkhard P, Gani D, Jenn T, Johnson C, Cook PF (2001) Characterization of the allosteric anion-binding site of $\mathrm{O}$-acetylserine sulfhydrylase. Biochemistry 40: 7446-7452.

Takahashi H, Yamazaki M, Sasakura N, Watanabe A, Leustek T, Engler JA, Engler G, Van Montagu M, Saito K (1997) Regulation of sulfur assimilation in higher plants: a sulfate transporter induced in sulfate-starved roots plays a central role in Arabidopsis thaliana. Proc Natl Acad Sci USA 94: 11102-11107.

Takahashi H, Watanabe-Takahashi A, Smith FW, Blake-KaIff M, Hawkesford MJ, Saito K (2000) The roles of three functional sulphate transporters involved in uptake and translocation of sulphate in Arabidopsis thaliana. Plant J 23: 171-182.

Vauclare P, Kopriva S, Fell D, Suter M, Sticher L, von Ballmoos P, Krahenbuhl U, den Camp RO, Brunold C (2002) Flux control of sulphate assimilation in Arabidopsis thaliana: adenosine $5^{\prime}$-phosphosulphate reductase is more susceptible than ATP sulphurylase to negative control by thiols. Plant J 31: 729-740.

Vestreng V, Myhre G, Fagerli H, Reis S, Tarrason L (2007) Twenty-five years of continuous sulphur dioxide emission reduction in Europe. Atmosph Chem Phys 7: 36633681.

Vidmar JJ, Schjoerring JK, Touraine B, Glass AD (1999) Regulation of the host1 gene encoding a high-affinity sulfate transporter from Hordeum vulgare. Plant Mol Biol 40: 883-892.

Vidmar JJ, Tagmount A, Cathala N, Touraine B, Davidian JE (2000) Cloning and characterization of a root specific high-affinity sulfate transporter from Arabidopsis thaliana. FEBS Lett 475: 65-69.

Wawrzynska A, Lewandowska M, Hawkesford MJ, Sirko A (2005) Using a suppression subtractive librarybased approach to identify tobacco genes regulated in response to short-term sulphur deficit. J Exp Bot 56: 1575-1590.

Wawrzynski A, Kopera E, Wawrzynska A, Kaminska J, Bal W, Sirko A (2006) Effects of simultaneous expression of heterologous genes involved in phytochelatin biosynthesis on thiol content and cadmium accumulation in tobacco plants. J Exp Bot 57: 2173-2182.

Wirtz M, Droux M (2005) Synthesis of the sulfur amino acids: cysteine and methionine. Photosynth Res 86: 345362.

Wirtz M, Hell R (2007) Dominant-negative modification reveals the regulatory function of the multimeric cysteine synthase protein complex in transgenic tobacco. Plant Cell 19: 625-639.

Xiang C, Oliver DJ (1998) Glutathione metabolic genes coordinately respond to heavy metals and jasmonic acid in Arabidopsis. Plant Cell 10: 1539-1550. 
Yamahuchi Y, Nakamura T, Harada E, Koizumi N, Sano H (1997) Isolation and characterization of a cDNA encoding sulfate transporter from Arabidopsis thaliana. Plant Physiol 113: 1463.

Yan X, Chen S (2007) Regulation of plant glucosinolate metabolism. Planta 226: 1343-1352.

Yoshimoto N, Inoue E, Watanabe-Takahashi A, Saito K, Takahashi H (2007) Posttranscriptional regulation of high-affinity sulfate transporters in Arabidopsis by sulfur nutrition. Plant Physiol 145: 378-388.

Yoshimoto N, Takahashi H, Smith FW, Yamaya T, Saito K (2002) Two distinct high-affinity sulfate transporters with different inducibilities mediate uptake of sulfate in Arabidopsis roots. Plant J 29: 465-473.

Zhao FJ, Hawkesford MJ, McGrath SP (1999) Sulphur assimilation and effects on yield and quality of wheat. $J$ Cereal Sci 30: 1-17.

Zhao FJ, Fortune S, Barbosa VL, McGrath SP, Stobart R, Bilsborrow PE, Booth EJ, Brown A, Robson P (2006) Effects of sulphur on yield and malting quality of barley. J Cereal Sci 43: 369-377. 